Article

\title{
Prosthesis Position after TAVI with Balloon-Expandable SAPIEN 3 in Bicuspid Aortic Valves
}

\author{
Philipp Breitbart ${ }^{1, *(\mathbb{D}}$, Jan Minners ${ }^{1}$, Martin Czerny ${ }^{2}$, Manuel Hein ${ }^{1}$, Franz-Josef Neumann ${ }^{1}$ and Philipp Ruile ${ }^{1}$ \\ 1 Division of Cardiology \& Angiology II, University Heart Center Freiburg • Bad Krozingen, University \\ Hospital Freiburg, 79189 Bad Krozingen, Germany; Jan.Minners@universitaets-herzzentrum.de (J.M.); \\ Manuel.Hein@universitaets-herzzentrum.de (M.H.); \\ Franz-Josef.Neumann@universitaets-herzzentrum.de (F.-J.N.); \\ Philipp.Ruile@universitaets-herzzentrum.de (P.R.) \\ 2 Department of Cardiovascular Surgery, University Heart Center Freiburg • Bad Krozingen, University \\ Hospital Freiburg, 79189 Bad Krozingen, Germany; martin.czerny@universitaets-herzzentrum.de \\ * Correspondence: Philipp.Breitbart@universitaets-herzzentrum.de; Tel.: +49-7633-4020; \\ Fax: +49-7633-402-9909
}

Citation: Breitbart, P.; Minners, J.; Czerny, M.; Hein, M.; Neumann, F.-J.; Ruile, P. Prosthesis Position after TAVI with Balloon-Expandable SAPIEN 3 in Bicuspid Aortic Valves. J. Clin. Med. 2021, 10, 2561. https:// doi.org/10.3390/jcm10122561

Academic Editors: Michael Henein and Jose P.S. Henriques

Received: 27 April 2021

Accepted: 8 June 2021

Published: 9 June 2021

Publisher's Note: MDPI stays neutral with regard to jurisdictional claims in published maps and institutional affiliations.

Copyright: (c) 2021 by the authors. Licensee MDPI, Basel, Switzerland. This article is an open access article distributed under the terms and conditions of the Creative Commons Attribution (CC BY) license (https:// creativecommons.org/licenses/by/ $4.0 /)$.

\begin{abstract}
Background: Prior data suggest a correlation between the position of transcatheter heart valves (THV) and the occurrence of complications after transcatheter aortic valve implantation (TAVI) in patients with tricuspid aortic valves (TAV). However, data including a detailed analysis of prosthesis positioning in bicuspid aortic valves (BAV) are limited. Therefore, the purpose of this study was to investigate THV position after TAVI in BAV. Methods: We evaluated the THV position in $50 \mathrm{BAV}$ and $50 \mathrm{TAV}$ patients (all received the balloon-expandable Sapien 3 prosthesis) using fusion imaging of pre- and post-procedural computed tomography angiography. According to the manufacturers' recommendations, a low implantation position was defined as $>30 \%$ of the prosthesis below the annulus. Results: THV position was appropriate in the majority of the patients within both groups $(90.0 \%$ for BAV vs. $96.0 \%$ for $\mathrm{TAV}, p=0.240)$. In BAV, we observed a more pronounced THV waist $(7.4 \pm 4.5 \%$ vs. $5.8 \pm 3.0 \%, p=0.043)$ and a lower average THV expansion $(91.9 \pm 12.2 \%$ vs. $95.5 \pm 2.7 \%$ of nominal expansion, $p=0.044)$. Conclusions: Accurate positioning in relation to the aortic annulus of the TAVI Sapien 3 prosthesis is possible in patients with BAV with results comparable to TAV. However, there is a more pronounced prosthesis waist and a lower average THV expansion in BAV.
\end{abstract}

Keywords: transcatheter aortic valve implantation; TAVI; bicuspid aortic valves; prosthesis positioning; computed tomography angiography; fusion imaging

\section{Introduction}

Bicuspid aortic valves (BAVs) are the most common congenital heart defect, with an overall incidence of $1-2 \%$, and are responsible for over $50 \%$ of symptomatic aortic valve stenoses in patients $<80$ years [1]. Nevertheless, up to $20 \%$ of elderly patients considered for transcatheter aortic valve implantation (TAVI) exhibit bicuspid valves [2]. However, most early major randomized trials investigating the TAVI procedure excluded BAV $[3,4]$.

An early study with a limited number of patients demonstrated the TAVI feasibility in BAV-patients with encouraging short- and intermediate-term clinical outcomes but questioned the long-term outcome due to suboptimal echocardiographic results [5]. Current data suggest that TAVI in BAV is safe and effective, especially in newer generations of prosthesis designs with improved outcomes comparable to those of tricuspid aortic valves (TAVs) [6-10]. Current large clinical trials included a proportion of 2-6\% of patients with BAV [11,12]. Asymmetric valve geometry may render prosthesis positioning difficult in clinical practice, leading to transcatheter heart valve (THV) malpositioning. This may lead to various complications, e.g., conduction disturbances or paravalvular leakage $[13,14]$. 
While THV position and characteristics were mostly examined in patients with TAV, data for TAVI in BAV are scarce so far. A prior study of our group demonstrated an exact three-dimensional visualization of the THV within the native annulus region after TAVI using a new fusion imaging method of pre- and post-procedural computed tomography angiography (CTA) [15]. With this method, we revealed deep implantation of the THV as a predictor for the new onset of conduction disturbances.

Therefore, this study aimed to investigate the THV position after TAVI in BAV compared to TAV using this fusion imaging method.

\section{Materials and Methods}

\subsection{Study Population}

Patients with an analyzable pre- and post-TAVI CTA and implanted Sapien 3 THV (Edwards Lifesciences Inc., Irvine, CA, USA) were included in this retrospective single-center study. In our institution, all eligible patients receive routine post-TAVI CTAs according to guidelines concerning thoracic aortic stent implantation [16], with the intention to identify possible (subclinical) complications, e.g., aortic injuries or thrombosis of the valves. Severe renal insufficiency, frailty, and others were contraindications for a post-procedural CTA [17].

Within the study population, 50 patients with a BAV were diagnosed in pre-TAVI CTA. These patients were compared with a 1:1-matched (regarding prosthesis size with $23 \mathrm{~mm}$, $26 \mathrm{~mm}$, and $29 \mathrm{~mm}$ Sapien 3) TAV control group. The study was approved by the local institutional review board (IRB number EF FR 472/12) and complies with the Declaration of Helsinki.

\subsection{Morphology of the Bicuspid Aortic Valves}

The morphology of the BAVs was classified in pre-TAVI CTA according to the scheme of Sievers and Schmidke [18]. The congenital BAVs were divided into 3 major types, depending on the number of cusps and the presence of raphes: 0 (without any raphes), 1 (one raphe), or 2 (two raphes) (Figure 1). Type 1 was subclassified regarding the localization of the raphe in $\mathrm{L} / \mathrm{R}$ with a raphe between the left $(\mathrm{L})$ and right $(\mathrm{R})$ coronary cusps, $\mathrm{L} / \mathrm{N}$ with raphe between the left and non-coronary $(\mathrm{N})$ cusps, or R/N. As previously described, we defined functional (acquired) as secondarily fused cusps due to the adhesion of the commissure between two cusps, presumably due to degenerative processes [7].

\subsection{Image Acquisition}

We performed retrospective ECG-gated contrast-enhanced pre- and post-TAVI CTAs (70 mL for pre- and $50 \mathrm{~mL}$ for post-TAVI CTA, Imeron 400, Bracco, Konstanz, Germany) with a second-generation, dual-source CT scanner (Somatom Definition Flash, Siemens Healthineers, Forchheim, Germany) with previously described CTA-protocols [17]. All post-TAVI CTAs were performed before discharge.

We used bolus tracking within the left atrium as the region of interest for beginning the scan. Reconstruction of images was conducted in $50 \mathrm{~ms}$ steps throughout the cardiac cycle; slice thickness was $1 \mathrm{~mm}$ with an increment of $0.8 \mathrm{~mm}$, applying a stent-specific reconstruction kernel B46f for post-TAVI CTA.

Images based on multiplanar reformations were analyzed at a post-processing workstation (Syngo Multimodality Workplace, Siemens Healthineers, Forchheim, Germany). 

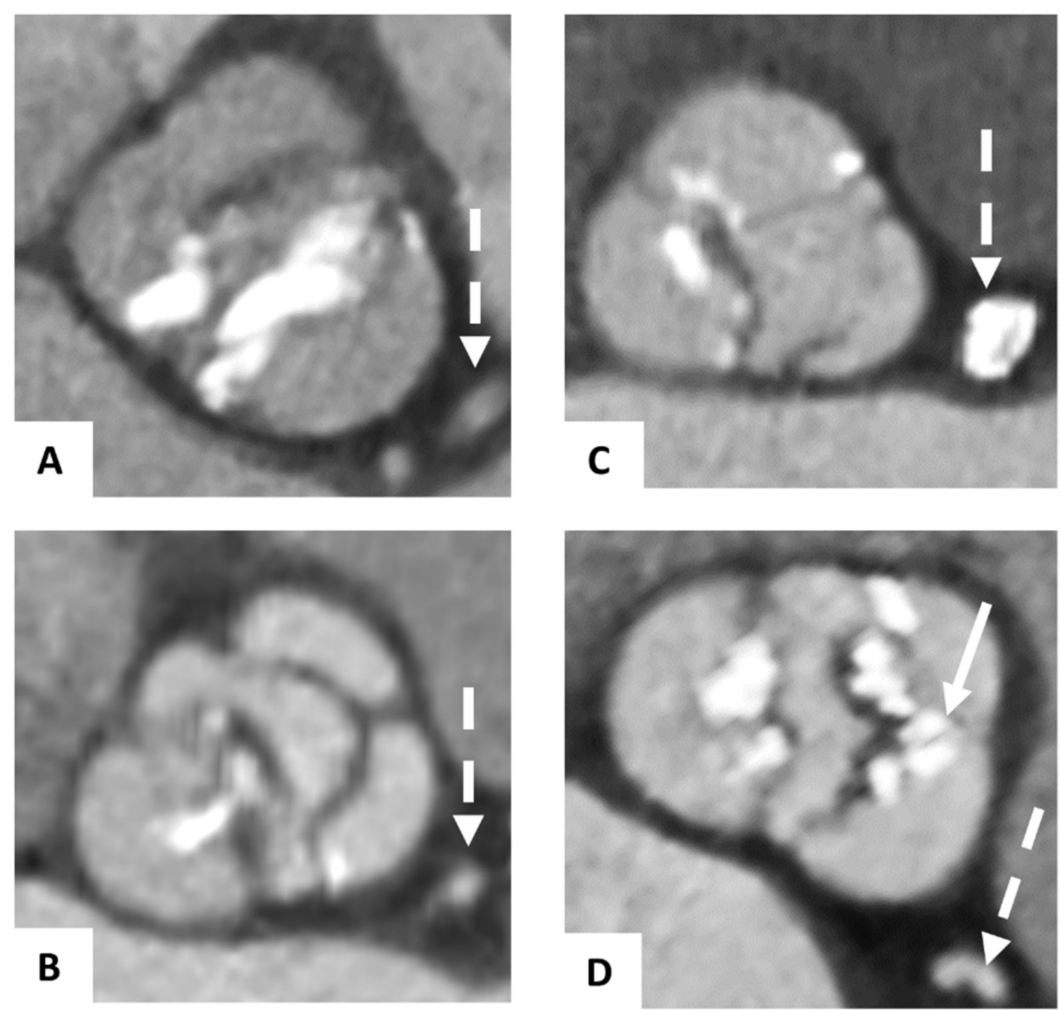

Figure 1. Classification of bicuspid aortic valves. Pre-TAVI contrast-enhanced CTA axial showing congenital bicuspid aortic valves classified according to the schema of Sievers and Schmidke with Type 0 (A), Type $1 \mathrm{~L} / \mathrm{R}$ (with raphe between the left and right coronary cusps) (B), Type $1 \mathrm{R} / \mathrm{N}$ (with raphe between the right and non-coronary cusps), (C) and a functional bicuspid aortic valve (D) with secondarily fused left and right coronary cusps due to severe calcification $(\rightarrow)$. The dashed arrow $(-->)$ is marking the left coronary artery system.

\subsection{Process of Fusion Imaging}

We assessed the final prosthesis position with fused images of pre- and post-procedural CTA, as previously described by our group [15]. In brief, we defined the annulus plane within the pre-TAVI CTA followed by a semi-automatic merging of these images with the post-TAVI CTA at the corresponding reconstruction time-point during systole. In the end, we performed a manual adaption of the fused images to achieve an optimal alignment of the annular region with their adjacent structures (Figure 2).

\subsection{Image Analysis}

Each image analysis was performed by two experienced readers (P.B. and P.R.). We conducted the following measurements on pre-TAVI images: within systole, the aortic annulus area and the area derived diameter were determined, and the annulus eccentricity was calculated as the largest diameter/smallest diameter. For each cusp, we performed a semiquantitative calcification assessment of the device-landing zone (grade 0: no calcification, grade 1: mild calcification as small calcified spots with a minimal diameter $\leq 2 \mathrm{~mm}$, grade 2 : moderate calcification as calcified spots with a minimal diameter more than $2 \mathrm{~mm}$, grade 3: severe calcification as large calcified formations more than $5 \mathrm{~mm}$ minimal diameter), as previously described (Figure 3) [19]. Measurements of total THV length, THV distance above and below the annulus (separately for the left coronary cusp, right coronary cusp, and non-coronary cusp) were conducted within the fused images to analyze the implantation depth. In the case of BAV without any raphes, we performed the measurements for the left coronary cusp adjacent to the ostium of the left coronary artery; for the right coronary cusp, adjacent to the ostium of the right coronary artery; for the non-coronary cusp, opposite of the middle between the left coronary and right 
coronary cusp. We defined the optimal THV position according to the manufacturers' recommendations as more than 70 percent of the prosthesis above (aortic) and less than 30 percent below (ventricular) the annulus plane.

Pre-TAVI CTA

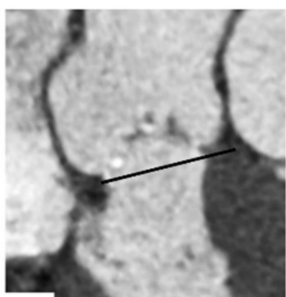

A

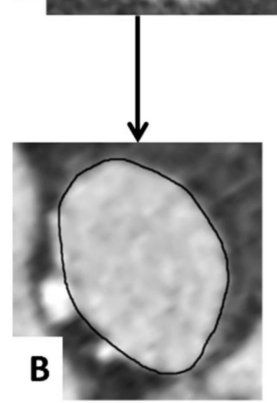

Post-TAVI CTA

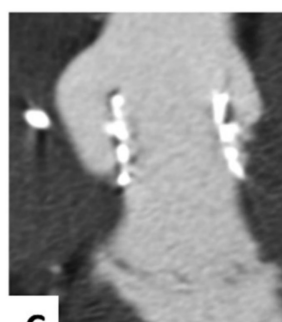

C

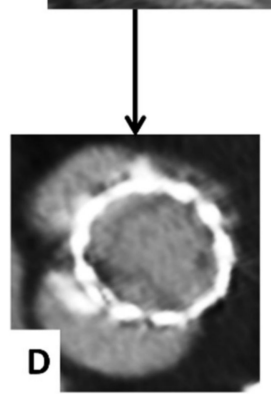

Fusion processing

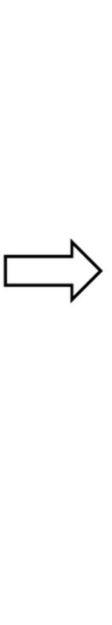

\section{Fused images of pre- \& post-TAVI CTA}

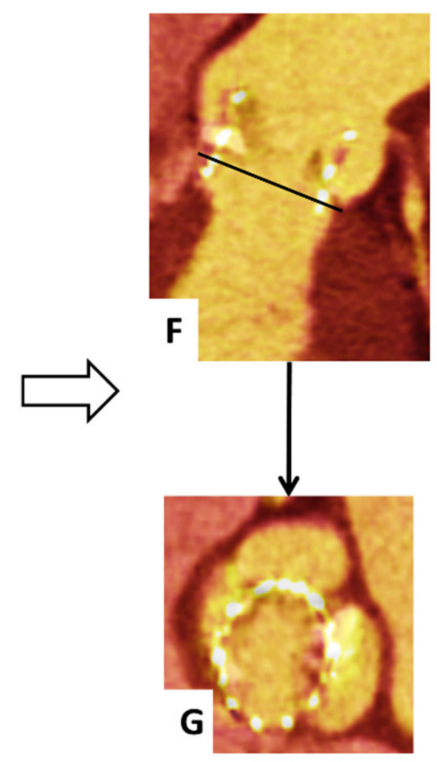

Figure 2. Visualization of fusion imaging of pre- and post-TAVI CTA. CTA axial and sagittal oblique reconstructions show the pre-TAVI images with delineating of the annulus plane $(\mathbf{A}, \mathbf{B})$ and post-TAVI images with the implanted Sapien 3 (C,D). Subsequently, the pre- and post-TAVI images were semi-automatically merged (E). Finally, the fused images were manually adapted to achieve an optimal alignment of the annular region in all reconstructions $(\mathbf{F}, \mathbf{G})$.
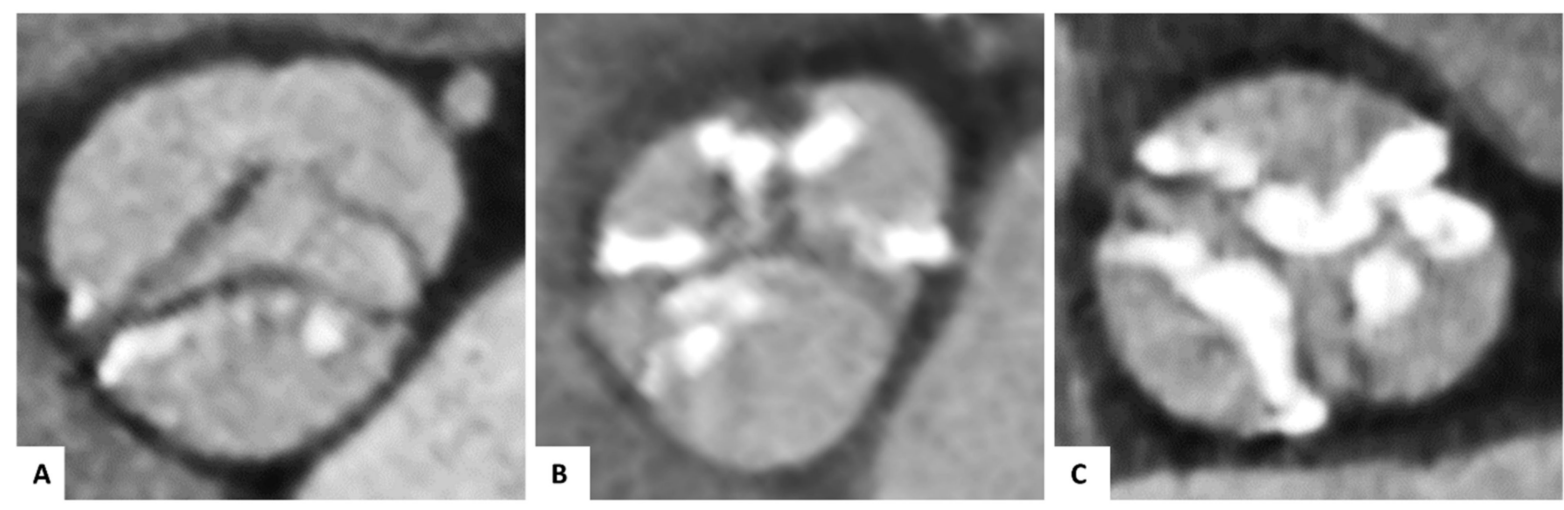

Figure 3. Semiquantitative calcification assessment of the device-landing zone. Pre-TAVI contrast-enhanced CTA of congenital and functional bicuspid aortic valves for visual calcification assessment with examples for mild (A), moderate (B), or severe $(\mathbf{C})$ calcification of the cusps regions.

The arctangent of (maximum-minimum stent center height above the annulus plane)/ (mean expanded THV diameter $\times 180 / \mathrm{Pi}$ ) defined the THV tilt in relation to the annulus plane. We assessed the expanded THV area using the mean value to evaluate the average prosthesis expansion as a percentage of the nominal area on three different heights (left ventricular outflow tract end, center of the stent, aortic end). The prosthesis oversizing $(\%)$ was determined as ((manufacturer-reported THV area/mean annulus area-1) $\times 100)$. 
For definition of the extent of prosthesis waist in percent area, measurements of the stent center compared to the average of the stent entry and exit were utilized.

\subsection{Statistical Analysis}

We performed all statistical analyses with SPSS software, Version 25.0 (IBM Corp., Armonk, NY, USA), reporting categorical data as frequencies or percentages and continuous variables as a mean with standard deviation or median with interquartile range. The $\chi 2$-test (for categorical variables), Student's $t$-test (for normally distributed continuous variables), Mann-Whitney-U test (non-normally distributed continuous variables in the comparison of BAVs with the control group), or Kruskal-Wallis test (non-normally distributed continuous variables in the comparison among the BAV subtypes) was used to test differences between the BAV and control group. Continuous variables were tested for normal distribution applying the Kolmogorov-Smirnov test. We defined a $p$-value $<0.05$ as statistically significant in all tests.

\section{Results}

During a period of 6 years (2014-2020), a post-TAVI CTA was conducted in 608 patients after implantation of a Sapien 3 THV within a median of 5 [interquartile range of 4-6] days after the procedure. Eleven post-TAVI CTAs were non-diagnostic for performing fusion imaging and THV position measurements due to reduced image quality. In 50 of these patients, a BAV was diagnosed. They were compared to 50 of a 1:1-matched control group as a randomized selection of the remaining 547 patients with TAV. The baseline characteristics of patients with BAV and the matched control group are presented in Table 1. Among the baseline variables, patients with BAV were significant younger (78.3 \pm 5.7 vs. $81.8 \pm 4.1$ years, $p=0.001$ ), whereas there were no significant differences regarding female gender ( 42.0 vs. $38.0 \%, p=0.683)$, logistic Euroscore $(15.5 \pm 13.3 \%$ vs. $14.2 \pm 9.5 \%, p=0.941)$, or atrial fibrillation ( 26.0 vs. $32.0 \%, p=0.509)$. However, patients with BAV had a higher calcification grade of the device-landing zone (5.0 $\pm 1.1 \mathrm{vs.} 4.4 \pm 1.3$, $p=0.019$ ). No major complications (death, stroke, myocardial infarction, major bleeding, contained/uncontained annular rupture, or THV embolization) occurred in both groups within the in-hospital period immediately after the procedure.

Table 1. Baseline, procedural and prosthesis-related characteristics of the entire study population, patients with bicuspid aortic valve, and the matched control group.

\begin{tabular}{|c|c|c|c|c|c|}
\hline & & All Patients $(n=100)$ & $\begin{array}{c}\text { Patients with Bicuspid } \\
\text { Valve }(n=50)\end{array}$ & $\begin{array}{l}\text { Matched Control } \\
\text { Group }(n=50)\end{array}$ & $p$-Value \\
\hline Age & (years) & $80.0 \pm 5.3$ & $78.3 \pm 5.7$ & $81.8 \pm 4.1$ & 0.001 \\
\hline Female & & $40(40)$ & $21(42)$ & $19(38)$ & 0.683 \\
\hline BMI & $\left(\mathrm{kg} / \mathrm{m}^{2}\right)$ & $26.8 \pm 4.6$ & $26.3 \pm 4.6$ & $27.3 \pm 4.6$ & 0.061 \\
\hline Logistic Euroscore & $(\%)$ & $14.8 \pm 11.5$ & $15.5 \pm 13.3$ & $14.2 \pm 9.5$ & 0.941 \\
\hline STS Score & $(\%)$ & $3.8 \pm 4.1$ & $3.5 \pm 2.6$ & $4.1 \pm 5.2$ & 0.443 \\
\hline Previous pacemaker & & $9(9)$ & $5(10)$ & $4(8)$ & 0.727 \\
\hline Atrial fibrillation & & $29(29)$ & $13(26)$ & $16(32)$ & 0.509 \\
\hline Oral anticoagulation & & $15(15)$ & $15(30)$ & $15(30)$ & 1.000 \\
\hline Aortic valve area & $\left(\mathrm{cm}^{2}\right)$ & $0.78 \pm 0.17$ & $0.80 \pm 0.19$ & $0.76 \pm 0.16$ & 0.383 \\
\hline Annulus diameter & $(\mathrm{mm})$ & $25.4 \pm 2.2$ & $25.7 \pm 2.4$ & $25.2 \pm 2.0$ & 0.705 \\
\hline Annulus eccentricity (CTA) & & $1.3 \pm 0.1$ & $1.3 \pm 0.1$ & $1.3 \pm 0.1$ & 0.125 \\
\hline $\begin{array}{l}\text { Grade of calcification of the } \\
\text { device-landing zone }\end{array}$ & $\begin{array}{l}\text { total } \\
\text { Left coronary cusp } \\
\text { Right coronary cusp } \\
\text { Non-coronary cusp }\end{array}$ & $\begin{array}{l}4.7 \pm 1.2 \\
1.5 \pm 0.6 \\
1.5 \pm 0.5 \\
1.8 \pm 0.6\end{array}$ & $\begin{array}{l}5.0 \pm 1.1 \\
1.5 \pm 0.7 \\
1.5 \pm 0.5 \\
2.0 \pm 0.5\end{array}$ & $\begin{array}{l}4.4 \pm 1.3 \\
1.4 \pm 0.5 \\
1.5 \pm 0.5 \\
1.6 \pm 0.5\end{array}$ & $\begin{array}{c}0.019 \\
0.478 \\
0.821 \\
<0.001\end{array}$ \\
\hline
\end{tabular}


Table 1. Cont.

\begin{tabular}{|c|c|c|c|c|c|}
\hline & & All Patients $(n=100)$ & $\begin{array}{c}\text { Patients with Bicuspid } \\
\text { Valve }(n=50)\end{array}$ & $\begin{array}{l}\text { Matched Control } \\
\text { Group }(n=50)\end{array}$ & $p$-Value \\
\hline $\begin{array}{l}\text { Ejection fraction } \\
\text { pre-interventional }\end{array}$ & $(\%)$ & $48.0 \pm 10.8$ & $46.4 \pm 11.7$ & $49.5 \pm 9.8$ & 0.262 \\
\hline Access route & $\begin{array}{l}\text { Transfemoral } \\
\text { Transapical }\end{array}$ & $\begin{array}{c}97(97) \\
3(3)\end{array}$ & $\begin{array}{c}49(98) \\
1(2)\end{array}$ & $\begin{array}{l}48(96) \\
2(4)\end{array}$ & 0.558 \\
\hline Prosthesis size & $\begin{array}{l}23 \mathrm{~mm} \\
26 \mathrm{~mm} \\
29 \mathrm{~mm}\end{array}$ & $\begin{array}{l}14(14) \\
54(54) \\
32(32)\end{array}$ & $\begin{array}{c}7(14) \\
27(54) \\
16(32)\end{array}$ & $\begin{array}{c}7(14) \\
27(54) \\
16(32)\end{array}$ & 1.000 \\
\hline Post-dilatation & & $12(12)$ & $6(12)$ & $6(12)$ & 1.000 \\
\hline Underfilling & & $12(12)$ & $6(12)$ & $6(12)$ & 1.000 \\
\hline New CD after TAVI ${ }^{a}$ & & $42(46.2)$ & $23(51.1)$ & $19(41.3)$ & 0.348 \\
\hline New PM after TAVI ${ }^{a}$ & & $19(20.9)$ & $9(20.0)$ & $10(21.7)$ & 0.838 \\
\hline Prosthesis oversizing & $(\%)$ & $7.0 \pm 10.0$ & $5.5 \pm 10.3$ & $8.5 \pm 9.5$ & 0.212 \\
\hline THV tilt & $\left({ }^{\circ}\right)$ & $5.4 \pm 3.4$ & $5.6 \pm 3.6$ & $5.2 \pm 3.4$ & 0.436 \\
\hline Extent of the THV waist & $(\%)$ & $6.6 \pm 3.9$ & $7.4 \pm 4.5$ & $5.8 \pm 3.0$ & 0.043 \\
\hline THV expansion & $(\%)$ & $93.7 \pm 9.0$ & $91.9 \pm 12.2$ & $95.5 \pm 2.7$ & 0.044 \\
\hline Mean expanded THV area & $\left(\mathrm{mm}^{2}\right)$ & $466.2 \pm 76.9$ & $457.6 \pm 79.7$ & $474.9 \pm 73.7$ & 0.166 \\
\hline MPG after implantation & $(\mathrm{mmHg})$ & $11.0 \pm 3.6$ & $11.3 \pm 3.9$ & $10.7 \pm 3.3$ & 0.334 \\
\hline Leaflet thrombosis & & $16(16)$ & $7(14)$ & $9(18)$ & 0.585 \\
\hline $\begin{array}{l}\text { Paravalvular } \\
\text { leakage }\end{array}$ & $\begin{array}{l}\text { None } \\
\text { Trivial } \\
\text { Mild } \\
\text { Moderate } \\
\text { Severe }\end{array}$ & $\begin{array}{c}47(47) \\
27(27) \\
26(26) \\
0(0) \\
0(0)\end{array}$ & $\begin{array}{c}22(44) \\
12(24) \\
16(32) \\
0(0) \\
0(0)\end{array}$ & $\begin{array}{c}25(50) \\
15(30) \\
10(20) \\
0(0) \\
0(0)\end{array}$ & 0.385 \\
\hline $\begin{array}{l}\text { Implantation depth below } \\
\text { annulus (mm) }\end{array}$ & $\begin{array}{c}\text { Mean } \\
\text { Left coronary cusp } \\
\text { Right coronary cusp } \\
\text { Non-coronary cusp }\end{array}$ & $\begin{array}{l}3.5 \pm 2.3 \\
2.9 \pm 2.6 \\
3.8 \pm 2.8 \\
3.8 \pm 2.7\end{array}$ & $\begin{array}{l}3.8 \pm 2.6 \\
3.2 \pm 2.9 \\
4.2 \pm 2.9 \\
4.1 \pm 3.1\end{array}$ & $\begin{array}{l}3.2 \pm 2.0 \\
2.6 \pm 2.2 \\
3.3 \pm 2.6 \\
3.5 \pm 2.3\end{array}$ & $\begin{array}{l}0.171 \\
0.273 \\
0.040 \\
0.607\end{array}$ \\
\hline Prosthesis position & $\begin{array}{l}\text { Optimal } \\
\text { Low }\end{array}$ & $\begin{array}{l}93(93) \\
7(7)\end{array}$ & $\begin{array}{l}45(90) \\
5(10)\end{array}$ & $\begin{array}{c}48(96) \\
2(4)\end{array}$ & 0.240 \\
\hline
\end{tabular}

Values are mean \pm standard deviation or $\mathrm{n}(\%)$. BMI: body mass index. CD: conduction disturbances. CTA: computed tomography angiography. MPG: mean pressure gradient. PM: permanent pacemaker. STS: Society of Thoracic Surgeons. THV: transcatheter heart valve. a Percent value based on patients without previous permanent pacemakers.

\subsection{Procedural-and Prosthesis-Related Characteristics}

Implanted prosthesis sizes were $23 \mathrm{~mm}$ in 14 (14\%) patients, $26 \mathrm{~mm}$ in 54 (54\%), and $29 \mathrm{~mm}$ in $32(32 \%)$. The procedural- and prosthesis-related characteristics of both groups are also presented in Table 1 . The rate of post-dilatation was $12.0 \%$ in both groups $(p=1.00)$. The analysis of oversizing or THV tilt revealed no significant differences between groups $(p=0.212$ and $p=0.436)$. However, there was a more pronounced waist $(7.4 \pm 4.5 \%$ vs. $5.8 \pm 3.0 \%, p=0.043)$ and a lower average expansion $(91.9 \pm 12.2 \%$ vs. $95.5 \pm 2.7 \%$ of nominal expansion, $p=0.044$ ) in the THV in patients with BAV. Furthermore, in BAV patients, the prostheses reached more into the left ventricular outflow tract at the right coronary cusp ( $4.2 \pm 2.9$ vs. $3.3 \pm 2.6 \mathrm{~mm}$ below annulus, $p=0.040)$. The mean implantation depth did not differ between both groups, and the majority of the THVs were implanted in an optimal position $(3.8 \pm 2.6$ vs. $3.2 \pm 2.0 \mathrm{~mm}$ below annulus, $p=0.171 ; 90.0 \%$ vs. $96 \%$ optimal position, $p=0.240$ ). We observed no significant differences in new-onset conduction disturbances or new pacemaker implantation $(p=0.348$ and $p=0.838)$. The 
amount of paravalvular THV leakage (PVL) was similar between both groups $(p=0.385)$; no patient revealed a moderate or severe PVL.

\subsection{Subanalysis of the Bicuspid Aortic Valves}

Among the BAV, $5(10 \%)$ were classified as Sievers Type 0, 34 (68\%) as Type 1 (left-right $(n=30)$; right-non $(n=4)$; left-non $(n=0))$ and $11(22 \%)$ as functional BAV. A separate presentation of the baseline-, procedural-, and prosthesis-related characteristics of the BAV patients, taking into account the individual bicuspid valve types, is shown in Table 2.

Table 2. Baseline, procedural, and THV position characteristics of the entire patient population with bicuspid aortic valves and for individual BAV types.

\begin{tabular}{|c|c|c|c|c|c|c|}
\hline & & $\begin{array}{l}\text { All Patients with } \\
\text { Bicuspid Valves } \\
\quad(n=50)\end{array}$ & Sievers $0(n=5)$ & Sievers $1(n=34)$ & $\begin{array}{l}\text { Functional } \\
\qquad(n=11)\end{array}$ & $p$-Value \\
\hline Annulus diameter & $(\mathrm{mm})$ & $25.7 \pm 2.4$ & $27.0 \pm 2.0$ & $25.3 \pm 2.2$ & $26.2 \pm 3.2$ & 0.221 \\
\hline Annulus eccentricity (CTA) & & $1.3 \pm 0.1$ & $1.1 \pm 0.2$ & $1.3 \pm 0.1$ & $1.3 \pm 0.2$ & 0.082 \\
\hline $\begin{array}{l}\text { Grade of calcification of the } \\
\text { device-landing zone }\end{array}$ & $\begin{array}{l}\text { total } \\
\text { Left coronary cusp } \\
\text { Right coronary cusp } \\
\text { Non-coronary cusp }\end{array}$ & $\begin{array}{l}5.0 \pm 1.1 \\
1.5 \pm 0.7 \\
1.5 \pm 0.5 \\
2.0 \pm 0.5\end{array}$ & $\begin{array}{l}5.3 \pm 0.6 \\
1.9 \pm 0.8 \\
1.8 \pm 0.7 \\
1.6 \pm 0.6\end{array}$ & $\begin{array}{l}5.0 \pm 1.2 \\
1.5 \pm 0.7 \\
1.4 \pm 0.4 \\
2.1 \pm 0.5\end{array}$ & $\begin{array}{l}5.0 \pm 1.0 \\
1.5 \pm 0.6 \\
1.7 \pm 0.5 \\
1.8 \pm 0.5\end{array}$ & $\begin{array}{l}0.677 \\
0.532 \\
0.089 \\
0.082\end{array}$ \\
\hline Prosthesis size & $\begin{array}{l}23 \mathrm{~mm} \\
26 \mathrm{~mm} \\
29 \mathrm{~mm}\end{array}$ & $\begin{array}{l}7(14) \\
27(54) \\
16(32)\end{array}$ & $\begin{array}{l}0(0) \\
1(20) \\
4(80)\end{array}$ & $\begin{array}{c}5(14.7) \\
21(61.8) \\
8(23.5)\end{array}$ & $\begin{array}{l}2(18.2) \\
5(45.5) \\
4(36.4)\end{array}$ & 0.143 \\
\hline Post-dilatation & & $6(12)$ & $3(60)$ & $1(2.9)$ & $2(18.2)$ & 0.001 \\
\hline Underfilling & & $6(12)$ & $0(0)$ & $5(14.7)$ & $1(9.1)$ & 0.605 \\
\hline Prosthesis oversizing & $(\%)$ & $5.5 \pm 10.3$ & $9.4 \pm 8.6$ & $6.2 \pm 9.9$ & $1.9 \pm 12.0$ & 0.342 \\
\hline THV tilt & $\left({ }^{\circ}\right)$ & $5.6 \pm 3.6$ & $4.4 \pm 2.9$ & $5.3 \pm 3.7$ & $7.0 \pm 3.0$ & 0.204 \\
\hline Hourglass form of the THV & $(\%)$ & $7.4 \pm 4.5$ & $3.9 \pm 6.4$ & $7.4 \pm 4.3$ & $8.9 \pm 3.7$ & 0.214 \\
\hline THV deployment & $(\%)$ & $91.9 \pm 12.2$ & $94.4 \pm 3.6$ & $90.6 \pm 14.6$ & $94.7 \pm 3.4$ & 0.421 \\
\hline Mean expanded THV area & $\left(\mathrm{mm}^{2}\right)$ & $457.6 \pm 79.7$ & $536.1 \pm 65.2$ & $443.3 \pm 70.7$ & $466.2 \pm 95.5$ & 0.098 \\
\hline MPG after implantation & $(\mathrm{mmHg})$ & $11.3 \pm 3.9$ & $9.8 \pm 2.3$ & $11.0 \pm 3.2$ & $13.0 \pm 5.7$ & 0.292 \\
\hline $\begin{array}{l}\text { Implantation depth below } \\
\text { annulus ( } \mathrm{mm})\end{array}$ & $\begin{array}{l}\text { Mean } \\
\text { Left coronary cusp } \\
\text { Right coronary cusp } \\
\text { Non-coronary cusp }\end{array}$ & $\begin{array}{l}3.8 \pm 2.6 \\
3.2 \pm 2.9 \\
4.2 \pm 2.9 \\
4.1 \pm 3.1\end{array}$ & $\begin{array}{l}4.7 \pm 4.2 \\
4.0 \pm 4.3 \\
3.4 \pm 4.2 \\
6.6 \pm 4.8\end{array}$ & $\begin{array}{l}4.0 \pm 2.4 \\
3.4 \pm 2.7 \\
4.9 \pm 2.4 \\
3.7 \pm 3.0\end{array}$ & $\begin{array}{l}3.1 \pm 2.3 \\
2.4 \pm 2.7 \\
2.7 \pm 3.5 \\
4.1 \pm 2.1\end{array}$ & $\begin{array}{l}0.474 \\
0.500 \\
0.130 \\
0.382\end{array}$ \\
\hline Prosthesis position & $\begin{array}{l}\text { Optimal } \\
\text { Low }\end{array}$ & $\begin{array}{c}45(90) \\
5(10)\end{array}$ & $\begin{array}{l}4(80) \\
1(20)\end{array}$ & $\begin{array}{c}31(91.2) \\
3(8.8)\end{array}$ & $\begin{array}{c}10(90.9) \\
1(9.1)\end{array}$ & 0.734 \\
\hline
\end{tabular}

Values are mean \pm standard deviation or $\mathrm{n}(\%)$. CTA: computed tomography angiography. MPG: mean pressure gradient. THV: transcatheter heart valve.

\section{Discussion}

To the best of our knowledge, this is the first study investigating the exact positioning of Sapien 3 THVs in bicuspid valves using fusion imaging of pre-and post-TAVI CTA within a cohort of BAV. Our data suggest that the positioning of these balloon-expandable devices in BAV shows a comparable accuracy to TAV. However, there is a more pronounced prosthesis waist and a lower average expansion of the THV in these patients.

A BAV is responsible for most isolated aortic valve replacements in younger patients but also causes stenosis in higher age groups with a proportion of up to $38 \%$ in patients between 71 and 80 years [20]. The clinical outcomes of TAVI using new-generation devices in BAV were favorable, with cumulative all-cause mortalities after 2 years comparable to TAV [21]. Prior data suggested a THV malposition as the leading cause of TAVI complications [13]. This called for a detailed analysis of THV position in patients with BAV. 


\subsection{Implantation Depth and Conduction Disturbances}

The majority of THVs in BAV were implanted in an optimal position according to manufacturers' recommendations, suggesting that TAVI with a Sapien 3 device in BAV is feasible and safe. Thus, our data confirm the hypothesis of other studies determining the THV position in post-TAVI CTA $[9,22]$. In these earlier trials, THV-provoked shadowing and post-interventional changes of the anatomy of the aortic root might have hampered the correct evaluation of THV positioning. In contrast, fusion imaging, as obtained in the current trial, allows for excellent visualization and assessment of the implanted THV as a three-dimensional object within the native aortic valve region [15] — the important novel findings of our study.

In view of the similar mean implantation depth between BAV and TAV, the lower prosthesis position in BAV next to the right coronary cusp needs to be interpreted cautiously. A correlation of a low prosthesis position, especially next to the right and non-coronary cusp, with new conduction disturbances post-TAVI, is reported $[15,23,24]$. Perlman et al. suggest that the high rate of pacemaker implantation $(23.5 \%)$ in their study may be associated with difficulty in achieving exact implantation heights as a result of the irregular shape of the leaflets on fluoroscopy, possibly resulting in lower implantation [7]. In line with these data, we observed numerically more new conduction disturbances in BAV (51\% vs. $41 \%$, $p=0.348$ ), yet without any appreciable impact on new pacemaker implantation. Due to the limited sample size, these observations that were far from statistical significance are difficult to interpret.

The higher amount of calcification of the device-landing zone in BAV, proven in this and prior studies, reflects the propensity for calcium deposition in these abnormally functioning valves, which is also a known predictor for new conduction disturbances and pacemaker implantations [9,25-27].

\subsection{Expansion and Prosthesis Waist}

We observed a lower average expansion of the THV in BAV as compared with TAV, which is in line with prior studies investigating Sapien 3 THV geometry $[9,22]$. This may be attributed to more pronounced calcification of the device-landing zone including calcified raphes [9]. Furthermore, we confirmed a more pronounced prosthesis waist after TAVI in $\mathrm{BAV}$, previously postulated by Kawamori et al. [9]. This might be caused by forceful balloon inflation leading to dog-boning at the edges and a more restricted expansion at the annular level in the case of a BAV. Previous data from our group suggest a more pronounced prosthesis waist as protective against early leaflet thrombosis after TAVI, whereas a lower average expansion predicts this phenomenon [28]. In the light of these results, further studies with larger patient cohorts are desirable to detect possible influences of BAV on the occurrence of LT.

\section{Limitations}

This study reports on a limited patient number of 50 patients with BAV. This might hamper a diagnosis of some minor differences of the THV position or patient-specific characteristics between BAV and TAV patients, though we tried to overcome this limitation by choosing a matched control group.

\section{Conclusions and Impact on Daily Practice}

Considering the increasing application of the TAVI procedure to younger patients with a greater proportion of $\mathrm{BAV}$, robust data for a reliable procedure in this subset are crucial. In this context, we demonstrate that the positioning accuracy of the balloon-expandable Sapien 3 THVs is adequate in patients with BAV. 
Author Contributions: P.B.: Conceptualization, Data curation, Formal analysis, Investigation, Validation, Writing—original draft, J.M.: Writing—review and editing, M.C.: Writing—review and editing, M.H.: Formal analysis, Investigation, F.-J.N.: Supervision, Writing-review and editing, P.R.: Conceptualization, Data curation, Validation, Writing-original draft. All authors have read and agreed to the published version of the manuscript.

Funding: This research received no external funding.

Institutional Review Board Statement: The study was approved by the local institutional review board (IRB number EF FR 472/12) and complies with the Declaration of Helsinki.

Informed Consent Statement: Informed consent was obtained from all subjects involved in the study.

Data Availability Statement: The data presented in this study are available on request from the corresponding author.

Conflicts of Interest: Franz-Josef Neumann reports that his institution has received research grants, consultancy fees, and speaker honoraria from Daiichi Sankyo, Astra Zeneca, Sanofi-Aventis, Bayer, The Medicines Company, Bristol, Novartis, Roche, Boston Scientific, Biotronik, Medtronic, Edwards und Ferrer. The remaining authors have no conflict of interest to declare.

\author{
Abbreviations \\ BAV Bicuspid aortic valve \\ CTA Computed tomography angiography \\ PVL Paravalvular THV leakage \\ TAV Tricuspid aortic valve \\ TAVI Transcatheter aortic valve implantation \\ THV Transcatheter heart valve
}

\title{
References
}

1. Ward, C. Clinical significance of the bicuspid aortic valve. Heart 2000, 83, 81-85. [CrossRef]

2. Roberts, W.C.; Janning, K.G.; Ko, J.M.; Filardo, G.; Matter, G.J. Frequency of Congenitally Bicuspid Aortic Valves in Patients $\geq 80$ Years of Age Undergoing Aortic Valve Replacement for Aortic Stenosis (with or without Aortic Regurgitation) and Implications for Transcatheter Aortic Valve Implantation. Am. J. Cardiol. 2012, 109, 1632-1636. [CrossRef] [PubMed]

3. Leon, M.B.; Smith, C.R.; Mack, M.J.; Miller, D.C.; Moses, J.W.; Svensson, L.G.; Tuzcu, E.M.; Webb, J.G.; Fontana, G.P.; Makkar, R.; et al. Transcatheter Aortic-Valve Implantation for Aortic Stenosis in Patients who Cannot Undergo Surgery. N. Engl. J. Med. 2010, 363, 1597-1607. [CrossRef] [PubMed]

4. Leon, M.B.; Smith, C.R.; Mack, M.; Makkar, R.; Svensson, L.G.; Kodali, S.; Thourani, V.H.; Tuzcu, E.M.; Miller, D.C.; Herrmann, H.C.; et al. Transcatheter or Surgical Aortic-Valve Replacement in Intermediate-Risk Patients. N. Engl. J. Med. 2016, 374, 1609-1620. [CrossRef] [PubMed]

5. Mylotte, D.; Lefevre, T.; Søndergaard, L.; Watanabe, Y.; Modine, T.; Dvir, D.; Bosmans, J.; Tchetche, D.; Kornowski, R.; Sinning, J.-M.; et al. Transcatheter Aortic Valve Replacement in Bicuspid Aortic Valve Disease. J. Am. Coll. Cardiol. 2014, 64, 2330-2339. [CrossRef]

6. Attinger-Toller, A.; Bhindi, R.; Perlman, G.Y.; Murdoch, D.; Weir-McCall, J.; Blanke, P.; Barbanti, M.; Sathananthan, J.; Ruile, P.; Gandolfo, C.; et al. Mid-term outcome in patients with bicuspid aortic valve stenosis following transcatheter aortic valve replacement with a current generation device: A multicenter study. Catheter. Cardiovasc. Interv. 2019, 95, 1186-1192. [CrossRef] [PubMed]

7. Perlman, G.Y.; Blanke, P.; Dvir, D.; Pache, G.; Modine, T.; Barbanti, M.; Holy, E.W.; Treede, H.; Ruile, P.; Neumann, F.-J.; et al. Bicuspid Aortic Valve Stenosis: Favorable Early Outcomes with a Next-Generation Transcatheter Heart Valve in a Multicenter Study. JACC Cardiovasc. Interv. 2016, 9, 817-824. [CrossRef]

8. Yoon, S.-H.; Maeno, Y.; Kawamori, H.; Miyasaka, M.; Nomura, T.; Ochiai, T.; Nemanpour, S.; Raschpichler, M.; Sharma, R.; Chakravarty, T.; et al. Diagnosis and Outcomes of Transcatheter Aortic Valve Implantation in Bicuspid Aortic Valve Stenosis. Interv. Cardiol. Rev. 2018, 13, 62-65. [CrossRef]

9. Kawamori, H.; Yoon, S.-H.; Chakravarty, T.; Maeno, Y.; Kashif, M.; Israr, S.; Abramowitz, Y.; Mangat, G.; Miyasaka, M.; Rami, T.; et al. Computed tomography characteristics of the aortic valve and the geometry of SAPIEN 3 transcatheter heart valve in patients with bicuspid aortic valve disease. Eur. Heart J. Cardiovasc. Imaging 2018, 19, 1408-1418. [CrossRef]

10. Halim, S.A.; Edwards, F.H.; Dai, D.; Li, Z.; Mack, M.J.; Holmes, D.R.; Tuzcu, E.M.; Thourani, V.H.; Harrison, J.K.; Brennan, J.M. Outcomes of Transcatheter Aortic Valve Replacement in Patients with Bicuspid Aortic Valve Disease: A Report from the Society of Thoracic Surgeons / American College of Cardiology Transcatheter Valve Therapy Registry. Circulation 2020, 141, 1071-1079. [CrossRef] 
11. Yoon, S.-H.; Ahn, J.-M.; Hayashida, K.; Watanabe, Y.; Shirai, S.; Kao, H.-L.; Yin, W.-H.; Lee, M.K.-Y.; Tay, E.; Araki, M.; et al. Clinical Outcomes Following Transcatheter Aortic Valve Replacement in Asian Population. JACC Cardiovasc. Interv. 2016, 9, 926-933. [CrossRef]

12. Mack, M.J.; Brennan, J.M.; Brindis, R.; Carroll, J.; Edwards, F.; Grover, F.; Shahian, D.; Tuzcu, E.M.; Peterson, E.D.; Rumsfeld, J.S.; et al. Outcomes Following Transcatheter Aortic Valve Replacement in the United States. JAMA 2013, 310, 2069-2077. [CrossRef] [PubMed]

13. Sherif, M.A.; Abdel-Wahab, M.; Stöcker, B.; Geist, V.; Richardt, D.; Tölg, R.; Richardt, G. Anatomic and Procedural Predictors of Paravalvular Aortic Regurgitation After Implantation of the Medtronic CoreValve Bioprosthesis. J. Am. Coll. Cardiol. 2010, 56, 1623-1629. [CrossRef] [PubMed]

14. Almeida, J.G.; Ferreira, S.M.; Fonseca, P.; Dias, T.; Guerreiro, C.; Barbosa, A.R.; Teixeira, P.; Carvalho, M.; Ferreira, W.; Ferreira, N.D.; et al. Association between implantation depth assessed by computed tomography and new-onset conduction disturbances after transcatheter aortic valve implantation. J. Cardiovasc. Comput. Tomogr. 2017, 11, 332-337. [CrossRef]

15. Ruile, P.; Pache, G.; Minners, J.; Hein, M.; Neumann, F.-J.; Breitbart, P. Fusion imaging of pre- and post-procedural computed tomography angiography in transcatheter aortic valve implantation patients: Evaluation of prosthesis position and its influence on new conduction disturbances. Eur. Heart J. Cardiovasc. Imaging 2018, 20, 781-788. [CrossRef] [PubMed]

16. Hiratzka, L.F.; Bakris, G.L.; Beckman, J.A.; Bersin, R.M.; Carr, V.F.; Casey, D.E., Jr.; Eagle, K.A.; Hermann, L.K.; Isselbacher, E.M.; Kazerooni, E.A.; et al. 2010 ACCF/AHA/AATS/ACR/ASA/SCA/SCAI/SIR/STS/SVM Guidelines for the Diagnosis and Management of Patients with Thoracic Aortic Disease: Executive Summary. Catheter. Cardiovasc. Interv. 2010, 76, E43-E86. [CrossRef] [PubMed]

17. Pache, G.; Schoechlin, S.; Blanke, P.; Dorfs, S.; Jander, N.; Arepalli, C.D.; Gick, M.; Buettner, H.-J.; Leipsic, J.; Langer, M.; et al. Early hypo-attenuated leaflet thickening in balloon-expandable transcatheter aortic heart valves. Eur. Heart J. 2015, 37, $2263-2271$. [CrossRef]

18. Sievers, H.-H.; Schmidtke, C. A classification system for the bicuspid aortic valve from 304 surgical specimens. J. Thorac. Cardiovasc. Surg. 2007, 133, 1226-1233. [CrossRef] [PubMed]

19. Breitbart, P.; Pache, G.; Minners, J.; Hein, M.; Schröfel, H.; Neumann, F.-J.; Ruile, P. Predictors for low TAVI-prosthesis position assessed by fusion imaging of pre- and post-procedural CT angiography. Clin. Res. Cardiol. 2021, 110, 93-101. [CrossRef]

20. Roberts, W.C.; Ko, J.M. Frequency by Decades of Unicuspid, Bicuspid, and Tricuspid Aortic Valves in Adults Having Isolated Aortic Valve Replacement for Aortic Stenosis, with or without Associated Aortic Regurgitation. Circulation 2005, 111, 920-925. [CrossRef] [PubMed]

21. Yoon, S.-H.; Bleiziffer, S.; De Backer, O.; Delgado, V.; Arai, T.; Ziegelmueller, J.; Barbanti, M.; Sharma, R.; Perlman, G.Y.; Khalique, O.K.; et al. Outcomes in Transcatheter Aortic Valve Replacement for Bicuspid Versus Tricuspid Aortic Valve Stenosis. J. Am. Coll. Cardiol. 2017, 69, 2579-2589. [CrossRef]

22. Tchetche, D.; de Biase, C.; van Gils, L.; Parma, R.; Ochala, A.; Lefevre, T.; Hovasse, T.; De Backer, O.; Sondergaard, L.; Bleiziffer, S.; et al. Bicuspid Aortic Valve Anatomy and Relationship with Devices: The BAVARD Mutlicenter Registry. Circ. Cardiovasc. Interv. 2019, 12, e007107. [CrossRef]

23. Schwerg, M.; Fulde, F.; Dreger, H.; Poller, W.C.; Stangl, K.; Laule, M. Optimized Implantation Height of the Edwards SAPIEN 3 Valve to Minimize Pacemaker Implantation After TAVI. J. Interv. Cardiol. 2016, 29, 370-374. [CrossRef]

24. Fraccaro, C.; Buja, G.; Tarantini, G.; Gasparetto, V.; Leoni, L.; Razzolini, R.; Corrado, D.; Bonato, R.; Basso, C.; Thiene, G.; et al. Incidence, Predictors, and Outcome of Conduction Disorders After Transcatheter Self-Expandable Aortic Valve Implantation. Am. J. Cardiol. 2011, 107, 747-754. [CrossRef] [PubMed]

25. Mauri, V.; Reimann, A.; Stern, D.; Scherner, M.; Kuhn, E.; Rudolph, V.; Rosenkranz, S.; Eghbalzadeh, K.; Friedrichs, K.; Wahlers, T.; et al. Predictors of Permanent Pacemaker Implantation after Transcatheter Aortic Valve Replacement with the SAPIEN 3. JACC Cardiovasc. Interv. 2016, 9, 2200-2209. [CrossRef] [PubMed]

26. Latsios, G.; Gerckens, U.; Buellesfeld, L.; Mueller, R.; John, D.; Yuecel, S.; Syring, J.; Sauren, B.; Grube, E. “Device landing zone” calcification, assessed by MSCT, as a predictive factor for pacemaker implantation after TAVI. Catheter. Cardiovasc. Interv. 2010, 76, 431-439. [CrossRef] [PubMed]

27. Fedak, P.; Verma, S.; David, T.E.; Leask, R.; Weisel, R.D.; Butany, J. Clinical and Pathophysiological Implications of a Bicuspid Aortic Valve. Circulation 2002, 106, 900-904. [CrossRef]

28. Breitbart, P.; Pache, G.; Minners, J.; Hein, M.; Schröfel, H.; Neumann, F.-J.; Ruile, P. Influence of prosthesis-related factors on the occurrence of early leaflet thrombosis after transcatheter aortic valve implantation. Eur. Heart J. Cardiovasc. Imaging 2020, 21, 1082-1089. [CrossRef] 